\title{
A Find of Transoceanic Pottery at Bwejuu Island of the Rufiji Delta and Mafia Island, Tanzania: More Clue to the Elusive Ancient Azania's Metropolis of Rhapta
}

\author{
Mandela Peter Ryano ${ }^{1,2, *}$, Felix Arkard Chami \\ ${ }^{1}$ Department of History and Archaeology, University of Dodoma, Dodoma, Tanzania \\ ${ }^{2}$ Department of Archaeology and Heritage Studies, University of Dar es Salaam, Dar es Salaam, Tanzania
}

Email address:

ryanojr@yahoo.com (M. P. Ryano)

${ }^{*}$ Corresponding author

\section{To cite this article:}

Mandela Peter Ryano, Felix Arkard Chami. A Find of Transoceanic Pottery at Bwejuu Island of the Rufiji Delta and Mafia Island, Tanzania: More Clue to the Elusive Ancient Azania's Metropolis of Rhapta. International Journal of Archaeology. Vol. 9, No. 1, 2021 , pp. $24-33$. doi: $10.11648 /$ j.ija.20210901.14

Received: January 8, 2021; Accepted: January 31, 2021; Published: April 7, 2021

\begin{abstract}
The island of Bwejuu is one of the islands of the Mafia archipelago on the central coast of Tanzania. It is only 15 $\mathrm{km}$ off the Rufiji Delta and its inhabitants carry out cultivation activities on the delta. The Rufiji delta has been considered by several scholars to be the location of the elusive ancient Azania's metropolis of Rhapta. Past research on the island established that it was of the 16th-18th centuries post-Swahili civilization. This research has verified that finding although underwater work on the south-east part discovered pottery attributed to ancient transoceanic activities, possibly arriving from either the Mediterranean region or probably Oman or Indian regions. Sites with trade remains from those regions have been discovered on the Delta and Mafia archipelago. Also, an underwater site with wall-like structures believed to be remains of a longsubmerged ancient settlement has recently been found in the northwestern waters of Mafia Island. The site has drawn attention of some archaeologists who believe it could be the long-lost metropolis of Rhapta. The new findings from Bwejuu Island may suggest that there are several trading sites in the region of the Mafia archipelago and the Rufiji Delta as outskirts of a large settlement which could be Rhapta. This study collected data through archaeological surveys and test excavations. Data analysis involved pottery attribute analysis and metric dating by thermoluminescence method.
\end{abstract}

Keywords: Mafia Archipelago, Bwejuu Island, Rufiji Delta, Transoceanic, Rhapta, Pottery

\section{Introduction}

This paper presents findings of a recent archaeological work conducted at Bwejuu Island on the Mafia archipelago on the Tanzanian central coast (figure 1). The study aimed at understanding the settlement history of the island which had been less known archaeologically. This small island was first examined archaeologically by the second author in 1997 [7]. Chami's work involved only survey through which pottery remains attributable to the post-Swahili period were found. However, he was of the opinion that the occupation of the island could be traced back to the $1300 \mathrm{CE}$, during the heydays of the Swahili towns of Kisimani Mafia and Kua on Mafia Island and Juani Island respectively. The island of Bwejuu became therefore a subject of future archaeological investigations to recover more information that would properly establish its settlement history. This work which was carried out in 2019 involved archaeological survey and excavations. The excavation work on the south-east of the island recovered pottery and beads of recent past, the 16th18th centuries CE, verifying Chami's previous findings. However, underwater survey on the south and south-east of the Island found good amount of pottery of transoceanic trade activities, some of which have been reported from other parts of the Mafia archipelago [6, 25, 19]. Three samples were subjected to thermoluminescence dating whereby two dates were found to be older than the 14th century CE, with one sample providing a date ranging the 1 st century BCE to 
the 7 th century $\mathrm{CE}$. This is a date for the ancient period when civilizations of the Mediterranean Sea, the Red Sea and the northern Indian Ocean were trading with Azania of East Africa.

\section{Research Problems}

First, Bwejuu is one of the inhabited islands of the Mafia archipelago. The island has received very limited archaeological research, having been only visited by Neville Chittick [14] in 1950s and surveyed by Felix Chami [7]. According to Chittick, Bwejuu Island was first settled by an Arab fisherman whose grandson Ali Mohamed was then the Jumbe/or head [16]. Although Chami reportedly found pottery remains attributed to the post-Swahili tradition, he opined that the island could have been occupied from 1300 $\mathrm{CE}$ [7]. The question that came up is whether we can know about the past settlement of Bwejuu.

The second problem is the location of Bwejuu Island at only $15 \mathrm{~km}$ offshore the Rufiji Delta and on the southwest of the Main Mafia Island. The Rufiji Delta and Mafia Island have been found to have many ancient archaeological sites, some of which have produced evidence of transoceanic trade connections. Scholars have pointed to the Rufiji Delta to be the location of the elusive metropolis of Rhapta $[2,8,12]$. After unsuccessful efforts to find traces of the town site, Chittick [12] concluded that the site has been buried or washed away. The question we had was how could research on the island of Bwejuu and its vicinity shed light on the elusive metropolis?

\section{Background to the Study}

Systematic archaeological research on the Mafia archipelago was pioneered in 1955 by Sir Mortimer Wheeler, Neville Chittick, Greville Freeman-Grenville and James Kirkman $[12,27]$. There was a notable focus on the stone ruined sites of Kisimani Mafia on the Main Island and Kua on Juani Island which were thought to be the earliest settlements on the archipelago [13, 18]. The former stone town site, thought to be older than the latter, was excavated by Chittick in 1957 [13]. On the basis of imported glazed pottery and Kilwa coins, the lowermost cultural layer was dated to the 13th century CE [Ibid]. Archaeological investigations carried out by Felix Chami and colleagues from 1997 through early 2000s revealed the presence on the archipelago of Early Iron Working settlements [4, 7]. The type-sites are Mlongo, Kitoni and Mtenga on the Main Island and Juani Primary School and Ukunju Cave on Juani Island. A number of sites of similar tradition were previously demonstrated on the opposite mainland coast [9] and inshore islands of Kwale and Koma [10].

Sites bearing evidence of pottery traditions that succeeded the EIW such as Triangular Incised Ware (TIW),
Plain Ware (PW) and Swahili have also been attested from a number of localities in Mafia [4, 5]. The archipelago has since received more archaeological works including those of Stephanie Wynne-Jones [28], Annalisa Christie [15], Alison Crowther and colleagues [16] and Abel Shikoni and colleagues [25]. Wynne-Jones [28] focused on the longterm history of the archipelago while Christie [15] dealt with the social context of marine resources exploitation by the Swahili communities. Alison Crowther and colleagues re-excavated EIW sites on Juani Island to examine the nature of early subsistence and long-distance trade on the archipelago [16]. Recently, underwater wall-like structures have reportedly been discovered by a diver in the Mafia waters off the northwestern coast of Mafia Island. The structures have been considered to be possible remains of Rhapta [3]. It was noted above that the Rufiji Delta area has been mostly pointed to by scholars as the possible location of the Azania's metropolis of Rhapta mentioned in Periplus Maris Erythraei and Ptolemy's Geographia [1, 2, 5, 12, 26] The 1 st century CE-Periplus Maris Erythraei alludes to the presence of Homerite Arabs at the emporium of Rhapta, speaking the language of the local people with whom they intermarried [2]. Efforts deployed into the Rufiji Delta in search of the lost metropolis of Rhapta found many sites of the Early Iron Age (EIA) Roman period some with Roman trade materials such as beads and glass [4, 22]. The Mafia archipelago which is located opposite the Rufiji Delta at just some $15 \mathrm{~km}$ offshore, falls within the geographical area in which Rhapta could have been physically placed. As noted above, the presence of EIA sites rich in exotic materials is a testimony that the area can potentially provide clues about the elusive ancient metropolis of Rhapta. The need for a proper archaeological interpretation of the underwater structures has ignited the need for continued archaeological work on the archipelago, in and around the submerged site. In response to this, the latest work has been carried out under the Mafia Archaeological Research Project funded by Thanda Tanzania Ltd where EIW site of Ukunju Cave on Juani Island [25] and Kisimani Mafia stone town site on Mafia Island [24] are among the sites examined. This recent research on Bwejuu Island was carried out under the auspices of the same project.

\section{The Location and Description of the Site}

Bwejuu Island $\left(7^{\circ} 56^{\prime} \mathrm{S}, 39^{\circ} 31^{\prime} \mathrm{E}\right)$ is one of the eight islands forming the Mafia archipelago located on the central coast of Tanzania, about $15 \mathrm{~km}$ offshore east of the Rufiji Delta. As one of the six inhabited islands of the archipelago, Bwejuu Island lies approximately $5 \mathrm{~km}$ off the southwestern shore of the Mafia (Main) Island and is Mafia's nearest point to the mainland coast (figure 1). 


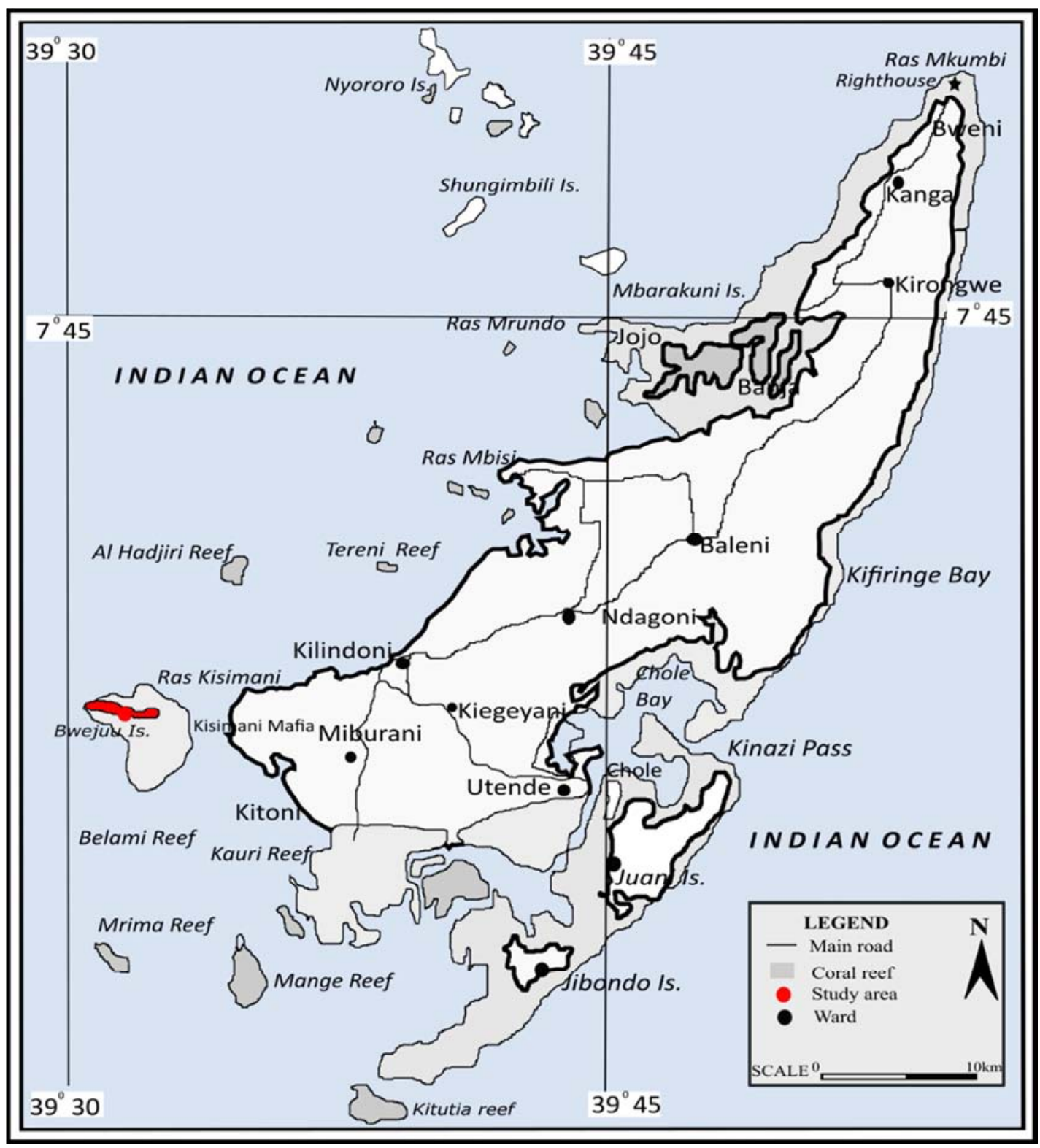

Figure 1. Map of the Mafia archipelago showing Bwejuu Island (Source: ArcGIS, 2020).

The island is a sand-bank upon an extensive coral reef, the pure sandy soil of which is productively sterile that supports only coconut. It is approximately $3 \mathrm{~km}$ east-west and less than $200 \mathrm{~m}$ north-south, but maps of 1820 s suggest that it was larger. A steady action of the south-east wind has made the Bwejuu island mobile [7: 210]. At the southern side of each end of the Island (east and west), there is one rocky islet, locally known as Kijiwe Nyara Kubwa (western end) and Kijiwe Nyara Ndogo (eastern end). The location of Bwejuu Island between the mainland coast and the Mafia archipelago prompted some scholars to consider it as the stepping land corridor through which the EIA first settlers of the archipelago crossed from the mainland [8]. Chami and Msemwa [10] hired simple boats and replicated the ancient crossing of the water area. The present population of Bwejuu Island is estimated to be over nine hundred, mainly subsisting on fishing and coconut while domestic animals such as chicken, goat and sheep are also found. Most of the inhabitants also cross the water to cultivate on the Rufiji delta and some have families thither.

Despite several attempts to dig deep wells, the search for freshwater has been a failure. Wells produce saline water which usually dry out at the height of dry seasons. Fresh water is obtained from two sources; first is rainwater collected by a built catchment tank, used cautiously and reserved for the dry seasons. Second, tape water brought by boats from either Kilindoni or the Rufiji Delta and sold as project of some entrepreneurs. It has been noted that, several attempts to dig for freshwater were fruitless. Excavation at one of the Shovel Test Pits we encountered freshwater at a depth of $220 \mathrm{~cm}$ below surface. Villagers were delighted by this first ever sign of freshwater and appealed to us that the test pit be left un-backfilled. Bwejuu Island is reached mainly by direct boats from Kilindoni, where boats land on the 
North shore and the South shore depending on the prevailing monsoon wind. The former is used during the south-east monsoon (Kusi in Swahili) blowing from April to August and the latter is used during the north-east monsoon (Kaskazi) that blows between November and March. Due to the extensive nature of the basal coral reef, the Island is easily reached at the high-tide when boats can reach up to the shore.

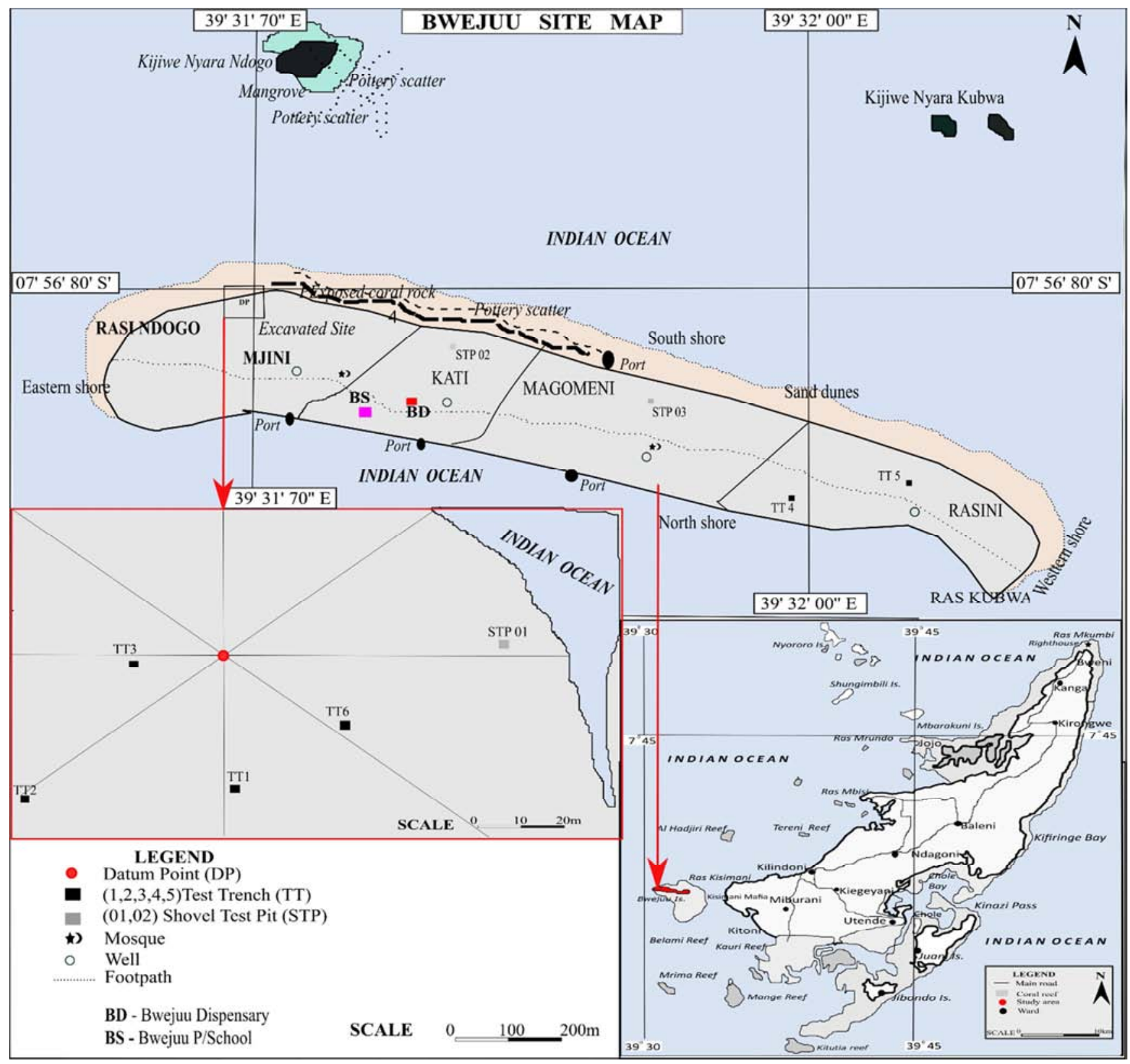

Figure 2. Map of Bwejuu Island showing excavated Test Trenches.

\section{Fieldwork and Methods}

The fieldwork was carried out in 2019, lasting three weeks between August and September. The first five and last two days were devoted to survey, on the land surface and on the ocean floor during low-tide. The survey strategy employed was simple unsystematic reconnaissance. The land surface was mostly poor in visibility due to shrub vegetation, except in a small area near the eastern tip of the island where a coconut farm has been weeded. This is the only area where scatters of pottery were found, thus warranting thorough examination by means of excavation. Potsherds found on the land surface were attributable to the near-modern periods, 18th-19th centuries. They appeared different from potsherds collected along the eastern half of the South shore of the island at a low water tide, which exhibit a fabric that is red in colour and fine texture reminiscent of the Roman pottery (see figure $5 \mathrm{a} \& \mathrm{~b}$; figure $7 \mathrm{c}$ ).

Unlike the South shore, which has produced a considerable amount of pottery, the North shore is remarkably poor in cultural materials. In the South shore, pottery seem to be confined to the eastern half. This area was surveyed 
intensively when the sea was at absolute low-tide and it extends from the shore for some $500 \mathrm{~m}$ to Kijiwe Nyara Ndogo. While potsherds collected along the shore may have been brought by wave erosion, those found at Kijiwe Nyara Ndogo seem to be in an intact context. The concentration of pottery, mostly found protruding above sea-bed, is remarkable at this locality. Due to the notable difference more stylistic- between sherds collected in the area along the shore and those from Kijiwe Nyara Ndogo, the two underwater sites were designated Site 1 (Kijiwe Nyara Ndogo) and Site 2 (inshore). These materials would prove to be the most interesting and intriguing of the findings from Bwejuu Island, as they appeared to be not only non-local but also of considerable antiquity. They seemed to be potentially of ancient time period, thus would provide clues about the recently discovered underwater site as well as shedding some light on the elusive metropolis of Rhapta. Potsherds recovered from test excavations are consistent with those found on the surface, attributed to the post-Swahili or later periods. Survey at Kijiwe Nyara Kubwa revealed that the small twined rocky islet, reachable on foot at low-tide, has a thin layer of greyish sandy soil that appeared devoid of archaeological content. A few coconut trees are present among the natural vegetation that includes large trees, under one of which objects such as pottery vessels, bottles and pieces of clothes have been assembled in a manner that suggests modern ritual activities.

Excavations started after the first five days of survey. As it has been noted, survey on the land surface revealed that potsherds are less concentrated and examples appear to be of recent or modern periods. The type of potsherds found on the underwater sites is strikingly absent on the land surface. The area that was selected for excavation, with scatters of potsherds, was mapped prior to the beginning of excavation. Mapping was conducted by the use of both the theodolite machine (SOKKIA C $3_{10}$ ) and a handheld Garmin GPS. The Datum Point (DP) was set at $7^{\circ} 56^{\prime} 80^{\prime \prime} \mathrm{S}, 39^{\circ} 31^{\prime} 73.3^{\prime \prime} \mathrm{E}$ and the main four grid lines (North, South, East, West) were established. On the basis of the rarity of materials on the surface, coupled with the sandy nature of sediments, excavations were conducted by means of Test Trenches (TT) and Shovel Test Pits (STPs). A total of six Test Trenches and three Shovel Test Pits was completed, four (TT1, TT2, TT3 and TT6) were established in the mapped area while two (TT4 and TT5) were set and excavated at the western extreme of the village.

Excavations were conducted vertically by arbitrary levels of $20 \mathrm{~cm}$ spits, but $40 \mathrm{~cm}$ spits in some occasions almost in all cases from the depth of $100 \mathrm{~cm}$ below the surface. TT1 is a $2 \times 2 \mathrm{~m}$ unit set at $23-25 \mathrm{~m}$ South and $3-$ $5 \mathrm{~m}$ East of the DP, some $8 \mathrm{~m}$ off the cliff. The rarity of materials on the surface was reflected underneath, with very few materials recovered from the top two excavation levels only. The Test Trench is completely sterile just below $40 \mathrm{~cm}$ below the surface. Excavation proceeded down through sterile sediments down to $100 \mathrm{~cm}$ depth where a square of $60 \mathrm{~cm}$ was established at the middle of the large unit. This small square was dug to the depth of $260 \mathrm{~cm}$ where the termination of the process was marked by the encounter of the water floor. Excavation of TT2 $(1.5 \times 1.5 \mathrm{~m}$ in size $)$ yielded no cultural materials, neither in situ nor from the straining of sediments. Digging was terminated at the depth of $160 \mathrm{~cm}$ below the surface, as the unconsolidated sandy walls began collapsing. TT3 sized $2 \times 2 \mathrm{~m}$ and was set on a mound of an old hut, $10 \mathrm{~m}$ south-west of the DP. Materials comprising beads and potsherds have been recovered from the top two excavation levels $(0-20 \mathrm{~cm}$ and $20-40 \mathrm{~cm})$ only, the excavation reaching a depth of $280 \mathrm{~cm}$ though it was narrowed at $180 \mathrm{~cm}$ depth to a $30 \mathrm{~cm}$ square pit in the middle of the Test Trench. For the next two test trenches, the work was moved towards the west for about a kilometer from the mapped area. Although there were no materials found on the surface, excavation was thought to provide a better picture. TT4 $(2 \times 2 \mathrm{~m}$ in size $)$ was established at an area where there is a coral reef outcrop ( $\left.7^{\circ} 56^{\prime} 58.6^{\prime \prime} \mathrm{S}, 39^{\circ} 30^{\prime} 91^{\prime \prime E}\right)$. Sediments of the trench from the surface down to a depth of $140 \mathrm{~cm}$, where the process ended at, are devoid of archaeological content. The coral outcrop is encountered at a depth of $45 \mathrm{~cm}$ and became more pronounces as excavation penetrated down, covering the entire trench. More testing was made in this western part of the Island with digging of another Test Trench (TT5). It was dug some $40 \mathrm{~m}$ from TT4 and near an old rainwater catchment tank. TT5 is a $2 \times 2 \mathrm{~m}$ unit that was dug down to $240 \mathrm{~cm}$ depth through sediments that lack archaeological content.

The last Test Trench (TT6), $2 \times 2 \mathrm{~m}$ in size, was set and dug in the area where the first three trenches were excavated. Its excavation proceeded by artificial levels of $20 \mathrm{~cm}$ spits, sinking down to $220 \mathrm{~cm}$ below surface at which the water floor was encountered. Cultural materials comprising glass beads and potsherds were recovered from the two upper levels, after which sediments became sterile. More subsurface testing has been done by means of STPs whereby three STPs were completed. One STP (STP-01) was set and dug further east, about $150 \mathrm{~m}$ away from the excavated area, while two (STP-02 and STP-03) were opened in the center of the village. These STPs are $1 \times 1 \mathrm{~m}$ square units dug by 20 cm arbitrary level-intervals to various depths. STP-01 and STP-02 were sunk down to the depth of $100 \mathrm{~cm}$ while STP03 (756'69.4"S, 39³1'20.6"E) reached down to a depth of $212 \mathrm{~cm}$, hitting the water level that marked the termination of the process. None of the STPs yielded any archaeological materials. Unlike in other holes where water is saline, the water encountered at STP-03 is fresh.

Winding up excavation with the Shovel Test Pits, the last two days of the fieldwork were devoted to survey along the South shore during the low-tide. Through intensive examination, a unique concentration of pottery was discovered at Kijiwe Nyara Ndogo (7०57'23"S, $\left.39^{\circ} 31^{\prime} 60.2^{\prime \prime E}\right)$. The potsherds, like those found along the shore, appear to be of imported origin, as they could not be attributed to any of the East African pottery traditions. 
Seemingly, these potsherds different from those found inshore. Pottery from both sites, unlike those from the land surface, appear to be high-profile and represent the main discovery of this work at Bwejuu Island.
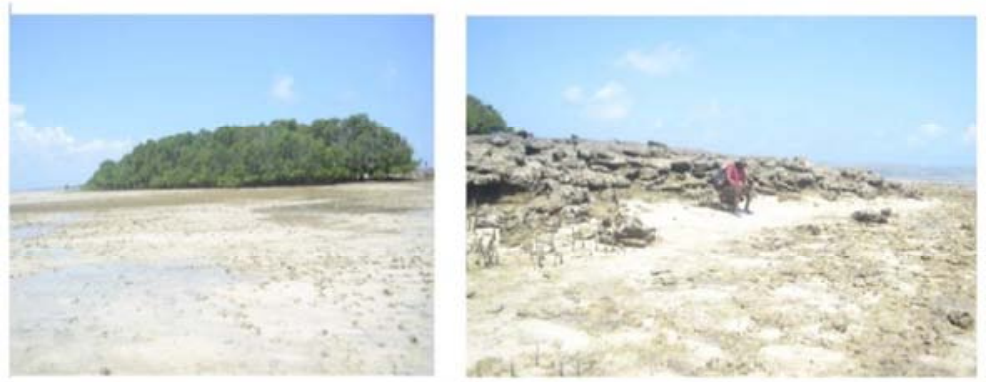

Figure 3. A view of Bwejuu underwater site 1 (Kijiwe Nyara Ndogo) (Field photos, 2019).

\section{Finds and Pottery Analysis}

Recovered materials consisted of pottery, glass beads and marine shells (Monetaria annulus), with pottery being by far predominant. The present paper is based on results of pottery and chronometric analyses. A total of 548 potsherds was collected, with 446 collected from survey and 102 recovered from excavations (Table 1). A great majority ( $n=409,91.7 \%)$ of survey pottery assemblage was collected from the underwater sites, Sites 1 and 2. As earlier stated, these were the most calling of the finds, potentially representing an interesting discovery. They have thus warranted to be the central focus of pottery attribute and chronometric analysis. The summary of the pottery collected in provided in the table below;

Table 1. Inventory of pottery collected from Bwejuu Island.

\begin{tabular}{|c|c|c|c|c|c|c|c|c|c|}
\hline \multirow{2}{*}{$\begin{array}{l}\text { Test Excavations } \\
\text { Depth }(\mathrm{cm}) \\
\end{array}$} & \multirow[b]{2}{*}{ TT1 } & \multirow[b]{2}{*}{ TT2 } & \multirow[b]{2}{*}{ TT3 } & \multirow[b]{2}{*}{ TT4 } & \multirow[b]{2}{*}{ TT5 } & \multirow[b]{2}{*}{ TT6 } & \multicolumn{2}{|l|}{ Survey } & \multirow{2}{*}{ Total } \\
\hline & & & & & & & Surface & Underwater & \\
\hline $0-20$ & 11 & 6 & 50 & - & - & 22 & & & \\
\hline $20-40$ & 3 & - & 7 & - & - & 3 & & & \\
\hline $40-60$ & - & - & - & - & - & - & 37 & 409 & \\
\hline $60-80$ & - & - & - & - & - & - & & & \\
\hline $80-100$ & - & - & - & - & - & - & & & \\
\hline Total & 14 & 6 & 57 & - & - & 25 & 37 & 409 & 548 \\
\hline
\end{tabular}

The pottery obtained from underwater sites appeared to be the most exciting. The second author, a specialist in East African Indian ocean potteries, considers most of the underwater pottery to be imported. The possibility of the sherds being of an Oman origin has been opined by Mark Horton (LaViolette, personal comm. with the second author). Other scholars consulted include Sunil Gupta of India who identified some of the similar pottery from the Ukunju Cave site and the discovered submerged site as from historic period of India [22, personal communication]. Giada Manzinali, an Italian who participated in excavations of ancient sites in Omani, also considered some of the sherds from Ukunju cave to be of Omani and the few Terra sigillata, similar to some examples of Bwejuu (figure 4), to be Roman [25]. The sherds collected from underwater, Kijiwe Nyara in particular, were found fairly well concentrated and the distribution pattern suggests that the area is a submerged site.

Pottery analysis adopted attribute analysis, examining various attributes that include vessel shape, decoration and temper. With regard to shape of the vessels, only 66 sherds qualify the criteria for shape determination with $54(81.8 \%)$ suggesting necked pots/jars (e.g. figure $4 \mathrm{a}-\mathrm{f}$ and figure $6 \mathrm{a}, \mathrm{c}, \mathrm{d}$, e, g) and $12(18.2 \%$ ) representing bowls (e.g. figure $4 y \&$ ac and figure $6 \mathrm{~b}, \mathrm{~h} \& \mathrm{~m})$. Some of these illustrations are similar to those from the Mediterranean Sea [20]. There are sixty-two sherds in the assemblage that bear decorations, made mostly by incision $(n=48,77.4 \%)$ and few cases of impression $(n=7$, $11.3 \%)$, groove $(n=3,4.8 \%)$, stamping $(n=2,3.2 \%)$ and punctate $(n=1,1.6 \%)$. Decorative motifs include bands of single arched shell-impressed lines (figure $4 a-d$ ), single overlapping-arcs of incision (figure 4e), multiple high-arc incision lines (figure $4 \mathrm{f} \& \mathrm{~g}$ ), in some cases based on multiple horizontal incision lines (figure 4f), multiple wavy incision lines (figure $4 \mathrm{~h} \& \mathrm{i}$ ) or double wavy incisions (4n) and single oblique incision lines (figure $40-q$ ). A singular case is noted where a sherd depicts the form of coating probably by lime mortar (figures $4 \mathrm{~s}, 5 \mathrm{c}$ ). Only two cases of decorated sherds have been observed in the pottery assemblage from Site 1 (figure $6 \mathrm{i} \& \mathrm{j}$ ). Both cases represent incision technique with single and multiple wavy line motifs being represented. It would seem that the decorated potteries, with coarse fabric, from Site 2 (figure 4 ) are local of the 16th/17th century or near modern, of the kinds that the second author had reported before. If the site was first settled in the ancient time it could also have had been settled in the near modern time. The site could have repeatedly been submerged several times as the island is moving, by the processes of erosion and deposition.

Examination, by unaided eyes, of texture and fabric colour has revealed that the use of medium-sized texture clay paste in making vessels is most frequently represented. Surface colours of the sherds are commonly red $(n=234,57.2 \%)$ and brown $(\mathrm{n}=166,40.6 \%)$, but few examples have buff colour 
$(n=9,2.2 \%)$. Inferring from the surface colors, the vessels were manufactured under high firing conditions. The temper, which is mostly medium in grade, derives from various raw materials such as rock grit, sand, grog/grot and the mixture of
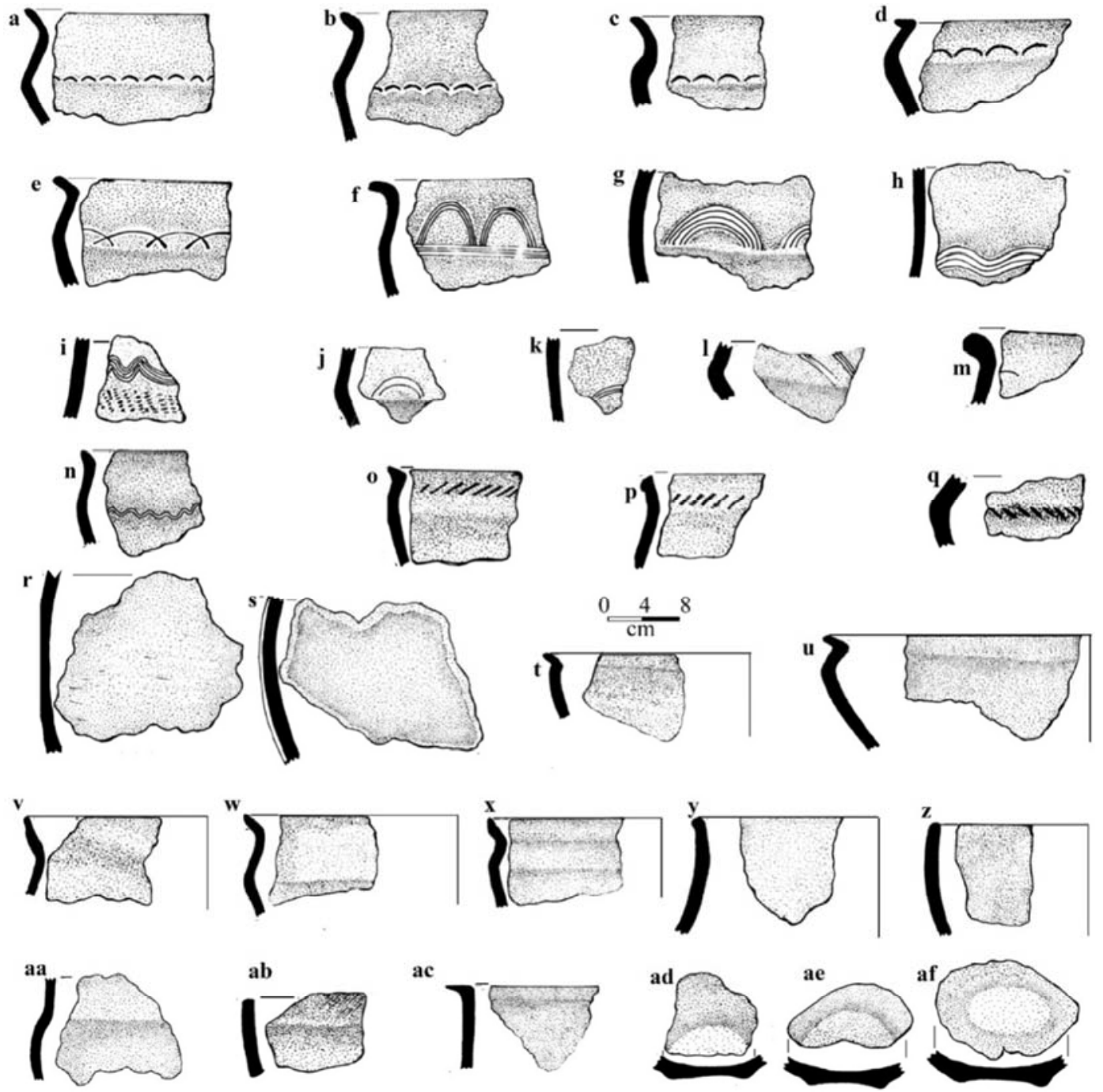

Figure 4. Illustrated sherds from Underwater Site 2, Bwejuu Island-shape and decoration: a-q local sherds; $r$-z \& aa-af imported.
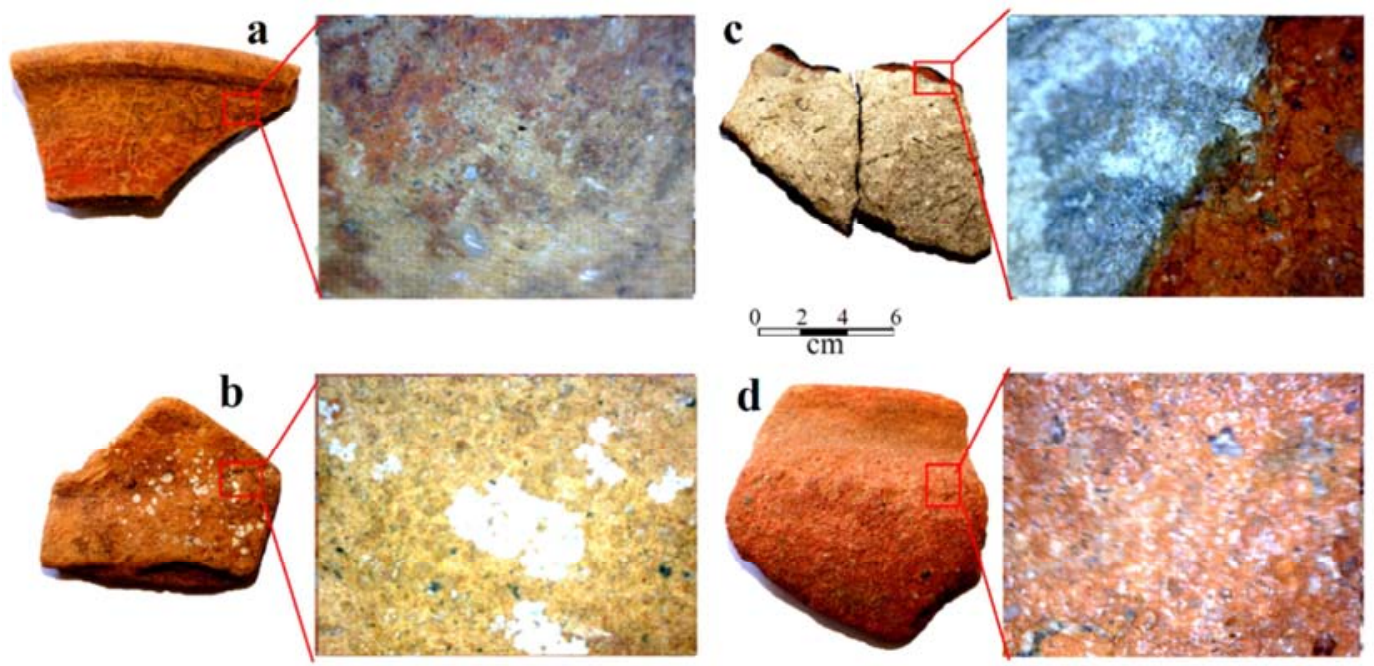

Figure 5. A close-up view of the texture of some imported sherds from Bwejuu Underwater Site 2. 

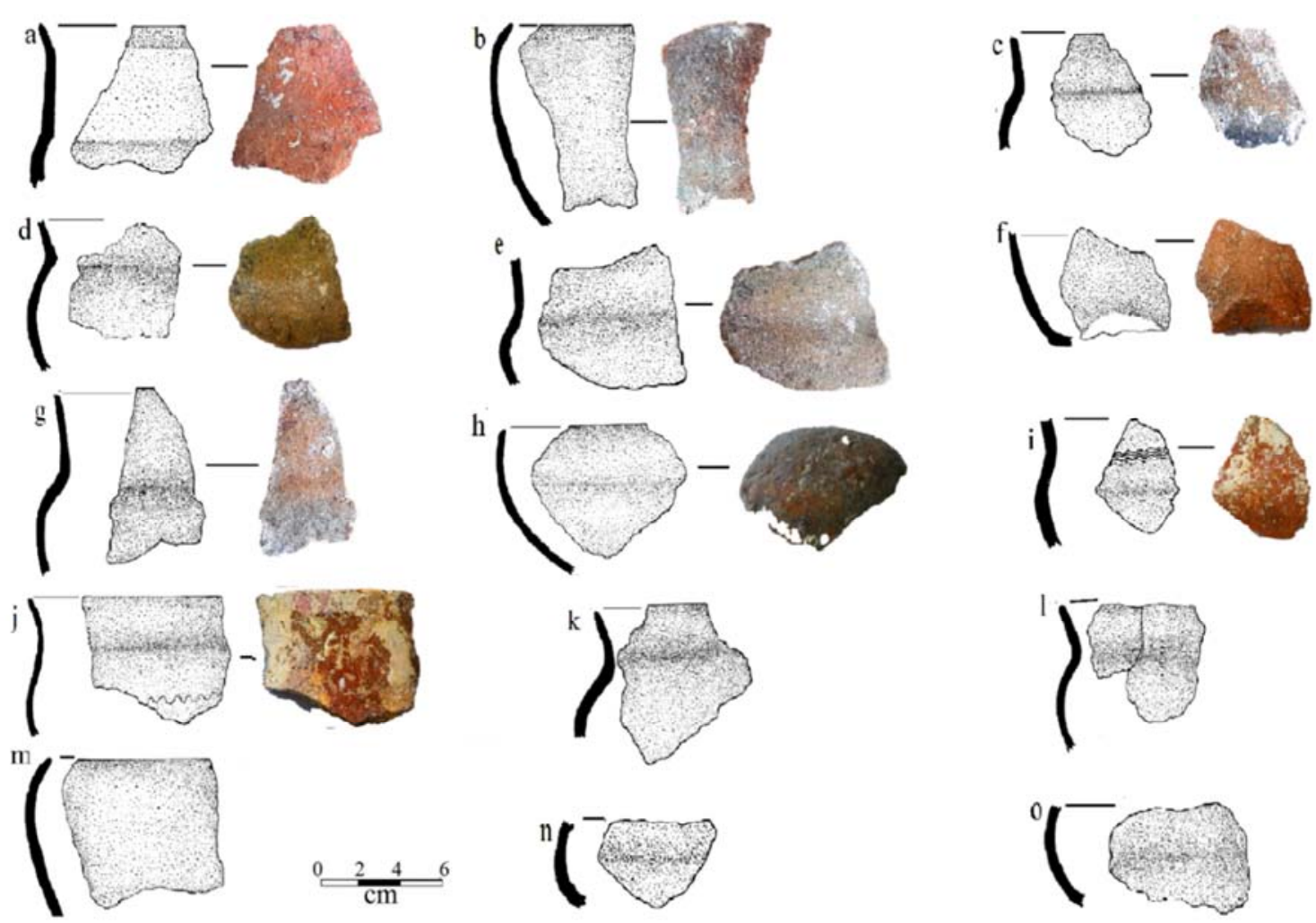

Figure 6. Some illustrated sherds from Bwejuu Underwater Site 1-Kijiwe Nyara Ndogo.
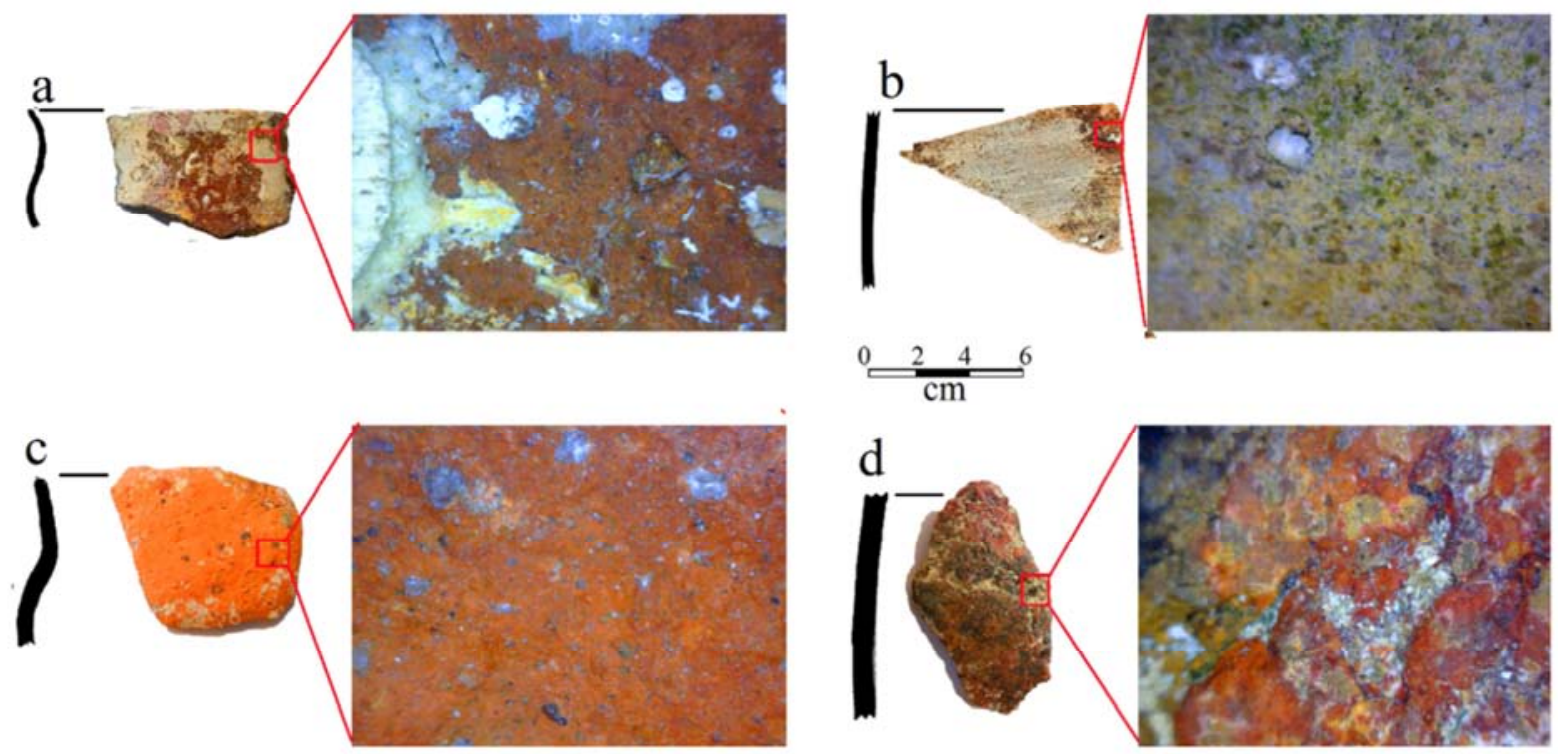

Figure 7. A close-up view of the texture of sherds from Bwejuu Underwater Site 1-Kijiwe Nyara Ndogo.

\section{Chronometric Dating}

Dating has been carried out by means of thermoluminescence (TL) technique. Three samples, two from Site 1 and one from Site 2, were submitted to the TecnArt laboratory of the
University of Torino, Piedmont Italy where dating was conducted. The thermoluminescence dating was the simple authenticity test to simply determine the age of the pottery objects. These samples have provided the following dates;

Table 2. Results of Thermoluminescence dating.

\begin{tabular}{|c|c|c|c|c|}
\hline Sample Number & Site & Lab. Number & Equivalent dose (Gy) & Age Range (centuries) \\
\hline 1 & Underwater Site 1 & Bwejuu Island_1 & $5.9 \pm 0.5$ & $1 \mathrm{BC}-\mathrm{VII} \mathrm{AD}$ \\
\hline 2 & Underwater Site 2 & Bwejuu Island_2 & $1.8 \pm 0.3$ & XIV-XVII AD \\
\hline 3 & Underwater Site 1 & Bwejuu Island_3 & $3.4 \pm 0.5$ & VIII-XIII AD \\
\hline
\end{tabular}




\section{Discussion}

The pottery assemblage recovered in the present study includes potsherds that are attributable to the post-15th century CE or near modern periods. These sherds are largely confined to the island's land surface and upper subsurface layers. Potsherds collected from the underwater area in the southeastern shore, which form the largest portion of the assemblage, seem to be of great antiquity and are inconsistent with the known local East African traditions. They are potentially the most interesting as they are attributable to the ancient transoceanic activities. None of these sherds is glazed and few examples are attributable to wheel-made method of pottery production. The pinkish and the red-brick fabric colour (figures $5 \mathrm{a} \& \mathrm{~b}$ and $7 \mathrm{c}$ ) of these sherds invites comparisons with the Roman Terra sigillata ware well discussed by Hayes [20]. Isolated pieces of red-brick fabric colour sherds attributed to the Roman ware have already been reported from some sites on the Mafia archipelago [25]. It is our suggestion that the imported pottery from Bwejuu probably derive their origin from the Mediterranean region, the Red Sea or Middle Eastern and Indian regions. Three dated samples of these sherds have given different dates, one, interestingly, dating to a period ranging the 1 st century $\mathrm{BCE}$ to the 7 th century $\mathrm{CE}$. Other samples have provided dates ranging 1300-1600 CE (Sample 2) and 700-1200 CE (Sample 3) periods. Whereas the date obtained from Sample 1 is of the ancient time, dates obtained from Samples 2 and 3 seem to be of the Swahili - or even post-Swahili- period, though none of the sherds exhibited the typical shape and decorative features of the Swahili and post-Swahili traditions.

It is reiterated that the Bwejuu pottery from the underwater sites attributed to a foreign origin suggest an early settlement on the small island that was involved in ancient transoceanic trading activities. This early settlement site was later submerged. Archaeological evidence of trade relations between the coast of East Africa and regions in the wider Indian Ocean and the Mediterranean/the Red Sea is still fragmentary but accumulating. The evidence significantly illuminates the classical sources, notably the Periplus Maris Erythraei and Ptolemy's Geographia, that served as the main source of our knowledge about involvement of East Africa in the international maritime trading networks from at least the early first millennium CE. These documentary sources allude to direct trading contacts between the East African coast and the Mediterranean region, the Red Sea and the northern Indian Ocean rim. Rhapta, now elusive, was reported by the Romans as the southernmost trading port on the East African coast, the region's largest city, known to them [23]. It was earlier noted that scholars have widely favoured the Rufiji Delta, on the central coast of Tanzania, to be the most likely physical location of Rhapta [2, 4, 12, 17, 23, 26]. The Periplus provides the location of the town at the mouth of a major navigable river bearing a name similar to that of the town. The Geographia of Claudius Ptolemy places the metropolis of Rhapta at latitude $7^{\circ} \mathrm{S}$, within which both the
Rufiji Delta and the Mafia archipelago are located. Like the modern day people of the Rufiji Delta and Bwejuu Island, Claudius Ptolemy in his Geographia identifies the people of the region as Rapfiji which is obviously an ancient corruption of Rufiji [4]. According to the Periplus Maris Erythraei, Azania was under Arab rule, being a possession of the Kingdom of the Sabaeans and Homerites in the southwestern part of the Arabian Peninsula-more or less the present day Yemen [2: 45]. The document hints on an active trade between Azania and the Himyaritic Kingdom, through its province of Mapharitis and its port of Muza -the foremost port in the kingdom's trade with Africa. The Periplus is suggestive that Homerites of Rhapta spoke the language of the Azanians with whom they intermarried [2:61].

Archaeological efforts by Chami on the Rufiji Delta in search of traces of the Azania's Rhapta resulted in the discovery of many EIA sites of the Rhapta period. As has been noted above, some of these sites yielded evidence of trade activities between the East African coast and the Roman Empire [21, 22]. Indeed, archaeological evidence pertaining to the Azania's trade with the Himyaritic kingdom, as alluded to by the classical documents has been reported [5, $19,21,25]$. We have already stated our opinion that the potteries discussed here probably derive their origin from either the Mediterranean region, Arabia or India. The thermoluminescence date obtained from Sample 1 of dated pottery samples (see Table 2) and those from Ukunju Cave elsewhere on Mafia where similar sherds were found fall within the chronological time period of the ancient Azania's trade port of Rhapta.

\section{Conclusion}

Results of this study suggest that the antiquity of Bwejuu Island had been settled from the ancient time, quite earlier than was previously thought. The pottery of the imported nature collected from the underwater area and dated to $1 \mathrm{st}$ century $\mathrm{BC}-7$ th century $\mathrm{AD}$ suggest a settlement that was involved in transoceanic activities, thus possible clues of the elusive ancient metropolis of Rhapta. Despite the absence of sherds attributable to Swahili tradition in collected assemblage, thermoluminescence dates suggest a continuous occupation of the Island from the ancient time through the 17 th century AD. Potsherds recognized as of post-Swahili and near modern traditions form the evidence of the settlements of the Island in those periods.

\section{Acknowledgements}

We would like to express our sincere gratitude to Thanda Tanzania Ltd for funding our fieldwork at Bwejuu Island. We are also deeply thankful to three field assistants, Hitson Pazza, Victor Venant and Nassoro Ramadhani and local assistants Mr. Kassim and Mr. Maharage, for their assistance in data collection. Special thanks are due to Mr. Hitson Pazza for his continued assistance in data analysis. 
Further, we are indebted to some institutions that had issued research permits for this fieldwork. These are; The University of Dar es Salaam, the Antiquities Division of the Ministry of Natural Resources and Tourism and the offices of the Pwani Regional Administrative Secretary and Mafia District Secretary as well as Kilindoni and Bwejuu local authorities.

\section{References}

[1] Bufure, A (2012) "Further Archaeological Research around Misimbo Lake, Rufiji Region, Tanzania," In Chami, F. and C. Radimilahy (eds), Studies in the African Past, Vol. 10, pp. 4763.

[2] Cason, L (1989) Periplus Maris Erythraei. Princeton: Princeton University Press.

[3] Chami, F (2021) "The Geographical extent of Azania," Theoria 68, 167: forthcoming

[4] Chami, F (2006) The Unity of African Ancient History: 3000 $B C$ to $A D$ 500. Dar es Salaam: E \& D Vision Publishing.

[5] Chami, F (2004b) "The Egypto-Graeco-Romans and Panchaea/Azania: sailing in the Erythraean Sea," In Lunde, P. and A. Porter (eds), Trade and Travel in the Red Sea Region: proceedings of the Red Sea Project. BAR International Series 1269.

[6] Chami, F (2004a) "The Archaeology of the Mafia Archipelago," In Chami, F., Pwiti, G. and C. Radimilahy (eds), Studies in the African Past, 4: 73-101.

[7] Chami, F (2000) "Further Archaeological Research on Mafia Island," Azania, Vol. 35: 208-214.

[8] Chami, F (1999) “The Early Iron Age on Mafia Island and its relationship with the mainland," Azania 34: 1-10.

[9] Chami, F. and Mapunda, B. (1998) "The 1996 archaeological reconnaissance north of the Rufiji Delta," Nyame Akuma 49: $62-78$.

[10] Chami, F. and Msemwa, P (1997b) "A New Look at Culture and Trade on the Azanian coast," Current Anthropology 38 (4): 673-677.

[11] Chami, F. and Msemwa, P. (1997a), "The Excavation at Kwale Island, South Dar es Salaam, Tanzania," Nyame Akuma 48: $45-56$.

[12] Chittick, N (1982) "Reconnaissance in Coastal Tanzania," Nyame Akuma 20: 57-58.

[13] Chittick, N (1961) "Kisimani Mafia: excavations at an Island settlement on the East African coast," Antiquities Division Occasional Paper. Dar es Salaam.
[14] Chittick, N (1957) "Mafia Group," Mafia Island District Book - History: Tanzania National Archives.

[15] Christie, A. (2011) "Exploring the Social Context of Maritime Exploitation in the Mafia Archipelago, Tanzania." Unpublished PhD Thesis: University of York.

[16] Crowther, A., M. Horton, A. Kotarba-Morley, M. Prendergast, E. Morales, M. Wood, C. Shipton, D. Fuller, R. Tibesasa, W. Mills and Boivin, N. (2014) "Iron Age agriculture, fishing and trade in the Mafia archipelago, Tanzania: new evidence from Ukunju Cave," Azania 49, No. 1: 21-44.

[17] Datoo, B (1970) "Rhapta, the location and importance of East Africa's first port," Azania 5: 65-75.

[18] Freeman-Grenville, G (1962) The Medieval History of the Coast of Tanganyika. London: Oxford University Press.

[19] Gupta, S. (2016) "Contact between East Africa and India in the first millennium CE," In G. Campbell (ed), Early Exchange between Africa and the Wider Indian Ocean World. Palgrave Series in Indian Ocean studies, pp. 157-171.

[20] Hayes, J. W (1997) Handbook of Mediterranean Roman Pottery. London: University of Oklahoma Press.

[21] Horton, M. and F. Chami (2018) "Swahili Origins," In S. Wynne-Jones and A. LaViolette (eds), The Swahili World, pp. 135-146. London: Routledge.

[22] Horton, M. and J. Middleton (2000), The Swahili: the social landscape of a mercantile society. Oxford: Blackwell Publishers.

[23] McLaughlin, R (2018) The Roman Empire and the Indian Ocean. Yorkshire: Pen and Books.

[24] Ryano, M. P, A. D. Shikoni, F. A. Chami and A. Sutton (2020) "The Cultural History of Kisimani Mafia Stone Town Site, Mafia Archipelago, Tanzania: findings from re-excavation of the site," Archaeologies.

[25] Shikoni, A., G. Manzinali, M. Peter, E. Kessy, T. Ombori and F. Chami (2019) "Report of the Re-excavation of Ukunju Limestone Cave in Juani, Mafia Archipelago, Tanzania: more evidence of ancient transoceanic trade connections," Man and Environment XLIV (2): 29-40.

[26] Tomber, R (2004) Indo-Roman Trade: from pots to pepper. London: Duckworth and Co.

[27] Wheeler, M (1955) “Archaeology in East Africa," Tanganyika Notes and Records 40: 43-47.

[28] Wynne-Jones, S (2006) "Reconstructing the Long-term History of the Mafia Archipelago," Unpublished Report Submitted to COSTECH and the Antiquities Department, Tanzania. 